\title{
An agent-based model of red colobus resources and disease dynamics implicates key resource sites as hot spots of disease transmission
}

\author{
Tyler R. Bonnell ${ }^{\mathrm{a}, *}$, Raja R. Sengupta ${ }^{\mathrm{a}}$, Colin A. Chapman ${ }^{\mathrm{b}, \mathrm{c}}$, Tony L. Goldberg ${ }^{\mathrm{d}}$ \\ a Dept. of Geography, McGill University, 805 Sherbrooke St. W., Montreal, QC, Canada H3A 2K6 \\ ${ }^{\mathrm{b}}$ Dept. of Anthropology \& McGill School of Environment, McGill University, Montreal, QC, Canada \\ ${ }^{c}$ Wildlife Conservation Society, Bronx, NY, USA \\ d Dept. of Pathobiological Sciences, School of Veterinary Medicine, University of Wisconsin-Madison, Madison, WI, USA
}

\section{A R T I C L E I N F O}

\section{Article history:}

Received 13 April 2010

Received in revised form 12 July 2010

Accepted 21 July 2010

Available online 17 August 2010

\section{Keywords:}

Red colobus

Spatially explicit agent-based model

SEIR model

Disease transmission

Kibale National Park

Uganda

\begin{abstract}
A B S T R A C T
The effect of anthropogenic landscape change on disease in wildlife populations represents a growing conservation and public health concern. Red colobus monkeys (Procolobus rufomitratus), an endangered primate species, are particularly susceptible to habitat alteration and have been the focus of a great deal of disease and ecological research as a result. To infer how landscape changes can affect host and parasite dynamics, a spatially explicit agent-based model is created to simulate movement and foraging of this primate, based on a resource landscape estimated from extensive plot-derived tree population data from Kibale National Park, Uganda. Changes to this resource landscape are used to simulate effects of anthropogenic forest change. With each change in the landscape, disease outcomes within the simulated red colobus population are monitored using a hypothetical microparasite with a directly transmitted life cycle. The model predicts an optimal distribution of resources which facilitates the spread of an infectious agent through the simulated population. The density of resource rich sites and the overall heterogeneity of the landscape are important factors contributing to this spread. The characteristics of this optimal distribution are similar to those of logged sections of forest adjacent to our study area.
\end{abstract}

(c) 2010 Elsevier B.V. All rights reserved.

\section{Introduction}

Increasing environmental change, driven by anthropogenic causes, is recognized as a major challenge to global health (Daszak et al., 2001; Patz et al., 2004; Jones et al., 2008). In the past 50 years, the size of the human population grew by 3.7 billion people (Potts, 2007) and in the next 50 years the global population is expected to surpass 9 billion people, with most of this growth occurring in the tropics (United Nations, 2009). This exponential growth of the human population forebodes many challenges to ecological systems, and continued growth is predicted to exacerbate the increasing demands for environmental products and services (Houghton, 1994). Consequently, demand for resources has increased, bringing about large-scale alterations of environmental conditions for wildlife. While some effects are obvious (e.g., deforestation, fragmentation, and habitat loss), others are likely to be subtle and difficult to quantify (e.g., future ecosystem composition and host/vector interactions). These effects, although complicated and difficult to generalize, are likely important drivers of emerging infectious diseases (Daszak and Cunningham, 2003; Plowright et al., 2008).

\footnotetext{
* Corresponding author. Tel.: +1 5149946541.

E-mail address: tyler.bonnell@mail.mcgill.ca (T.R. Bonnell).
}

Species and populations in the order Primates are particularly suitable for investigating such complex issues because of the large amount of information already available on their ecology, and because primate species are in decline throughout the world as a result of anthropogenic pressures (Chapman and Peres, 2001; Struhsaker, 2005; Mittermeier et al., 2007). Habitat destruction and hunting are thought to be the main factors driving the declines in primate populations (Mittermeier et al., 2007). However, these same anthropogenic changes can also dramatically alter host parasite interactions and are thus a concern for primate health (Formenty et al., 1999; Hahn et al., 2000; Graczyk et al., 2002; Chapman et al., 2005a; Goldberg et al., 2008b). The health of nonhuman primates is, in turn, of specific concern for human public health, due to the high risk that primates pose as reservoirs of zoonotic pathogens (Wolfe et al., 2007; Davies and Pedersen, 2008). This is illustrated by such pathogens as the human immunodeficiency virus (HIV; the cause of AIDS) (Hahn et al., 2000) and Plasmodium falciparum (the cause of virulent malaria) (Rich et al., 2009), both of which trace their origins to primates. In a recent study on the origins of major human infectious diseases, Wolfe et al. (2007) found that even though non-human primates constitute $0.5 \%$ of all vertebrates, their zoonotic transmission has contributed about $20 \%$ of the major human infectious diseases.

Red colobus (Procolobus rufomitratus) of Kibale National Park, Uganda, offer an ideal modeling system for examining the effects 
of habitat change on primate disease dynamics. Forty years of longterm data exist on their ecology, demography, and responses to anthropogenic change (Struhsaker, 1997; Chapman et al., 2005b). Additionally, the health of the red colobus has received considerable recent attention (Chapman et al., 2007; Goldberg et al., 2008a, 2009). This research has revealed evidence of transmission of disease agents between red colobus and humans (Goldberg et al., 2008b) and has highlighted the important role that fragmented landscapes play in augmenting parasitism within the red colobus population (Gillespie and Chapman, 2006).

Our goal in conducting this research is to examine how the spatial distribution of resources in a forest habitat affects the transmission of parasites within a red colobus population. Based on decades of observations, we suspect resource distribution to influence the transmission of parasites, based on observations of how red colobus use their habitats, where they choose to forage, how social groups organize, and rates of contact between social groups. Red colobus live in social groups in which movement appear to be largely driven by foraging for food. Red colobus are folivorous primates, whose foods vary in spatial aggregation based on individual tree species and on tree size (Chapman and Chapman, 2002). The characteristics of forests habitats are therefore important in determining the amount and distribution of resources for these primates, and hence, movement behaviour of groups. To test ideas about how forest compositions, and therefore variation in the distribution of these resources, could affect disease transmission within a population of red colobus we created a simulation model. Our objectives are then to use this simulation model to input a resource landscape upon which a simulated red colobus population, built with detailed behavioural data, can forage, allowing us to test landscape effects on parasite transmissions at a population level.

To construct this simulation model, an agent-based modeling (ABM) framework was used (Grimm and Railsback, 2005; Sengupta and Sieber, 2007). This approach has been used as an effective tool in simulating primate group behaviour (Te Boekhorst and Hogeweg, 1994; Hemelrijk, 2002; Bryson et al., 2007; Sellers et al., 2007), as well as infectious disease spread among primates (Nunn et al., 2008; Nunn, 2009). The overall construct of our model follows previous theoretical constructs of agent-based models which were focused on spatially explicit epidemiological simulation(Bian, 2004; Roche et al., 2008). We also make use of recent software advances linking ABM models with GIS (geographic information system) capabilities, allowing more detailed geographies to be incorporated implicitly, which allows these simulations to link spatial and temporal processes (Brown et al., 2005); for examples see, Bennett and Tang (2006), Perez and Dragicevic (2009) and KramerSchadt et al. (2009). Linking spatial and temporal processes has been recognized as crucial for addressing questions regarding landscape effects on disease (Ostfeld et al., 2005). In this case it allows us to link long-term forest data from our study area to a wealth of behavioural and epidemiological data for red colobus.

\subsection{Study site and data collection}

We focus on the red colobus living inside Kibale National Park, located in western Uganda. Kibale is composed of moistevergreen forest $\left(\sim 795 \mathrm{~km}^{2} ; 0^{\circ} 13^{\prime}-0^{\circ} 41^{\prime} \mathrm{N}\right.$ and $30^{\circ} 19^{\prime}-30^{\circ} 32^{\prime}$ E), that receives approximately $1697 \mathrm{~mm}$ (1990-2009) of rain each year distributed among two rainy seasons (Chapman and Chapman, unpublished data). We focus on a subsection of the park (Kanyawara K-30 250 ha) where detailed studies of red colobus group movement in relation to habitat quality have been conducted (Chapman et al., 2001; Chapman and Chapman, 2002; Snaith and Chapman, 2005, 2008), as well as studies on forest properties for the past 40 years (Struhsaker, 1997; Chapman et al., 2010). We use tree data from three time periods $(1989,1999$, and 2006), where
26 plots $(200 \mathrm{~m} \times 10 \mathrm{~m}$ ) were used to record identity and diameter at breast height (DBH) of trees larger than $10 \mathrm{~cm} \mathrm{DBH}$.

\section{The model}

The simulation model was developed using Repast Simphony 1.2 .0 software (http://repast.sourceforge.net/) combined with open source GIS software from JTS (Vivid Solutions Inc. www.vividsolutions.com/jts). The model description follows the ODD (Overview, Design concepts, Details) protocol for describing individual- and agent-based models (Grimm et al., 2006).

\subsection{Purpose}

The purpose of the model is to test the effects that resource distribution has on parasite transmission within a population of red colobus.

\subsection{State variables and scales}

The model is composed of three agents: the landscape, the host, and the microparasite. The model's base is the landscape where individual resource polygons make up a grid surface. A scale of $30 \mathrm{~m} \times 30 \mathrm{~m}$ grids was chosen, as this roughly estimates the average canopy size of the trees in which a large proportion of the group will feed, such that we assume foraging decisions are made at approximately this scale. Each polygon contains state variables, current amount of resources, and maximum resource levels.

The host, red colobus, forages on this surface, represented as a point in a continuous space, moving from resource polygon to resource polygon and contains state variables, energy level, and the number of neighbours needed to be considered safe from predation. Each red colobus agent also contains spatial memory and builds its own list of remembered sites and estimates of resources at these sites, in real time. Additionally, the red colobus agent is considered to be in one of four states representing the progression of disease, following a SEIR model (Hethcote, 2000). Specifically, the red colobus is either (S) susceptible to infection, (E) exposed but not yet infectious, (I) infectious to other hosts, and (R) recovered with immunity developed against this disease.

The microparasite agent, with a maximum of one within a host agent, can successfully infect another host, as determined by a probability function based on distance to the next host. The microparasite agent contains state variables; host primate and maturity level of infection. The microparasite characteristics were modeled after a general class of parasites that are directly transmitted between hosts, through contact and proximity, in which there transmission probabilities are relatively high. We aim here to represent the general behaviour of multiple classes of infectious agents that are transmitted by direct contact, such as filoviruses, poxviruses, or retroviruses (the latter two of which have been documented in Kibale red colobus (Goldberg et al., 2008a, 2009) or close interactions (e.g., respiratory aerosols), such as metapneumoviruses or respiratory syncytial viruses, which have recently been shown to impact ape conservation across Africa (Kaur et al., 2008; Kondgen et al., 2008). We emphasize that we do not model any specific agent, but rather create a generalized framework that can be adapted to future efforts targeting specific agents.

The scale of the model is established so that one time step in the model represents one half hour, in which red colobus agents, 264 agents as part of 5 distinct social groups, forage on a 225 ha grid surface. The model is then run, starting with the infection of one red colobus agent, until the microparasite agents goes extinct or the model reaches 6 months. The 6 months limit was chosen 
as population wide exposures, within our simulations, generally occurred within this time period.

\subsection{Process overview and scheduling}

The model is intended to simulate a novel parasite for which the primate hosts have no previous exposure. Time is modeled in discrete time steps, where each step is preformed in the same sequence. Each day is considered to be 26 half hour steps for a total of $13 \mathrm{~h}$, as red colobus are diurnal and are generally only active from 07:00 to 20:00 (Struhsaker, 1975). A time step of half an hour was chosen as this is the unit of measurement used in our longterm field observations of red colobus behaviour (Struhsaker, 1975; Snaith and Chapman, 2008). Within each time step, each primate agent will, in turn, go through its steps, followed by the parasite agents. At the end of the step the resource agents perform a re-grow step (Fig. 1).

\subsection{Design concepts}

The model is driven by the interaction between the landscape, the red colobus, and the microparasite. The landscape affects the way in which the red colobus forage, including movement and contact rates between groups; movement and contact rates in turn affect transmission rates of the microparasite through the population.

\subsubsection{Adaption}

The red colobus agent is the only agent considered that displays adaptive behaviour. It can adapt to balance its needs to gain safety within a group against the increased food competition experienced by being a part of the group (Snaith and Chapman, 2008). It accomplishes this, within our model, by measuring its food intake. When there is sufficient food intake, the red colobus agent will value safety within the group; predation pressures are the assumed driver behind the red colobus' need for safety in numbers, however, there is no specific predation within the model. When food intake is less than the ideal, the primate is assumed to be more prone to take risks and values feeding more than security within the group. This assumption is derived from the observation that red colobus groups tend to spread out during periods of food scarcity and contract during periods of food abundance (Snaith and Chapman, 2008).

\subsubsection{Emergence}

Red colobus agents in the simulation model form part of a specific social group, of which there are numerous groups in the system. Each group is only tied by mutual safety requirements, there are no other interactions (e.g., territoriality, intergroup dominance), which is consistent with our current understanding of red colobus socio-ecology (Struhsaker, 1975, 2010; Snaith and Chapman, 2008). The lack of strict territorial behaviour is critical for our assumptions of how transmission will occur, as groups of red colobus often forage within close proximity of each other, occa-

\section{Simulation model

Start of Step $\Rightarrow \begin{gathered}\text { Primate } \\ (\mathbf{1} \ldots \mathrm{n}) \text { Step }\end{gathered} \Rightarrow \begin{gathered}\text { Microparasite } \\ (\mathbf{1} \ldots \mathrm{n}) \text { Step }\end{gathered} \Rightarrow \begin{gathered}\text { Resource } \\ (\mathbf{1} \ldots \mathrm{n}) \text { Step }\end{gathered} \Rightarrow$ End of Step

Primate Agent
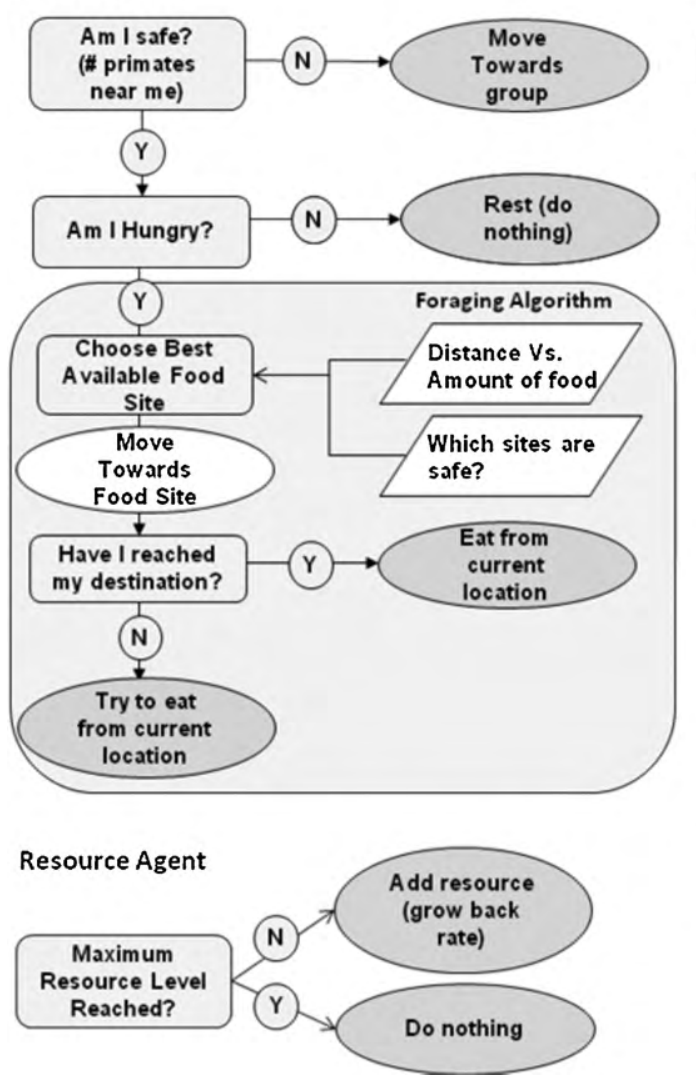

Microparasite Agent

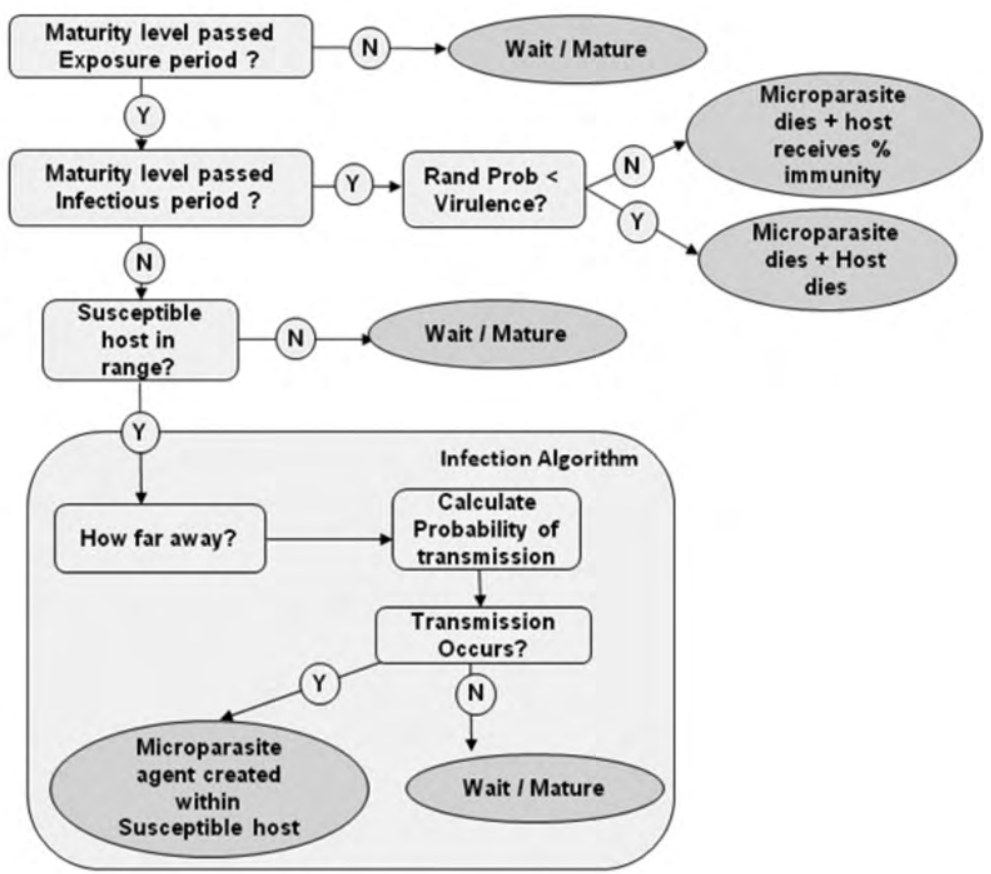

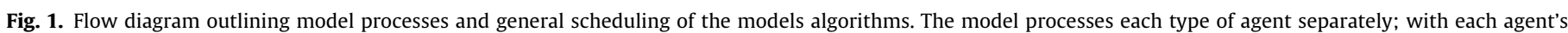
decision tree described below (details on the decision tree are discussed in Section 2.6). Shaded boxes represent an end point is reached in the decision tree. 


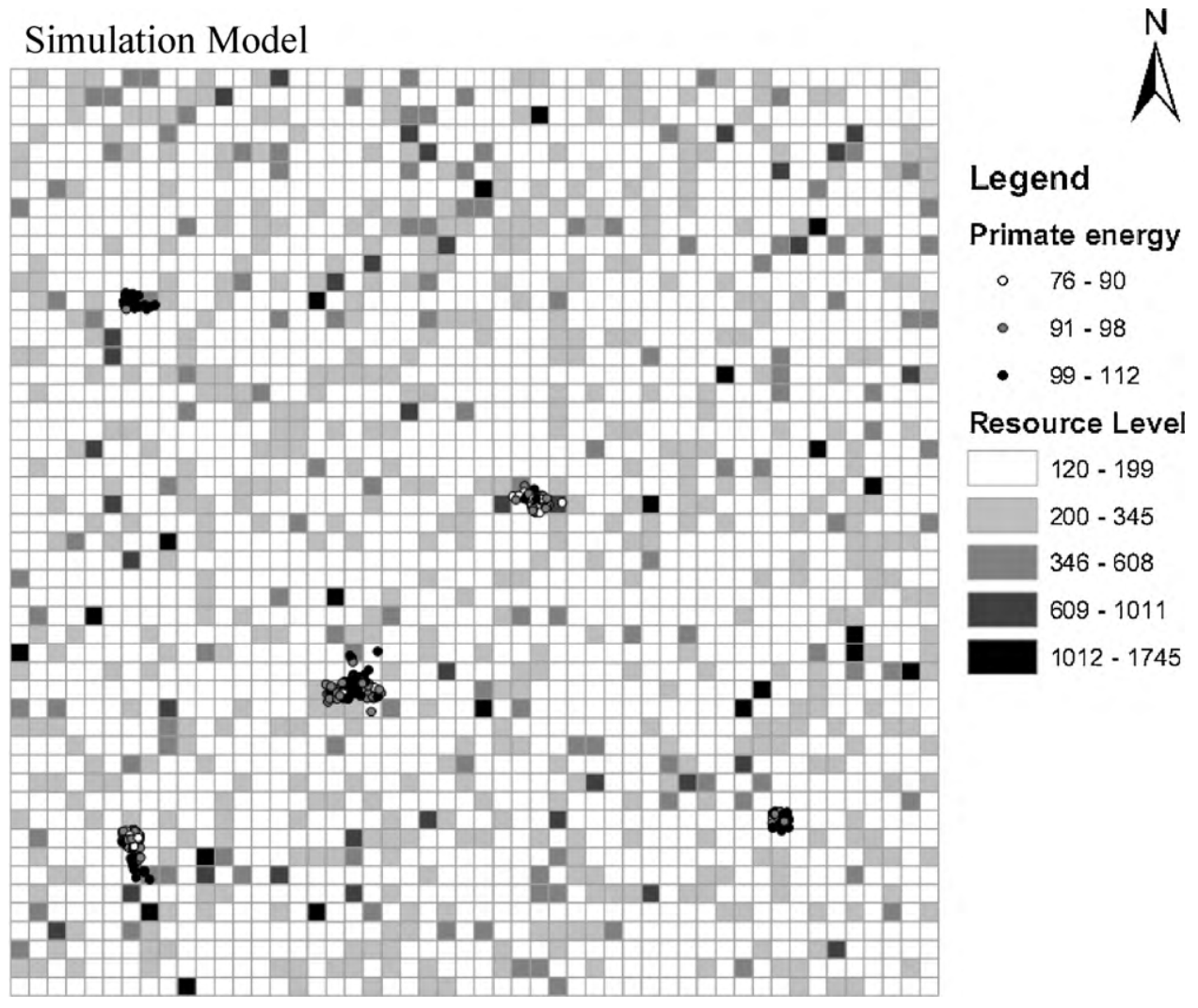

Fig. 2. Simulation environment: individual red colobus agents are represented by circles, resources are represented by grid squares.

sionally within the same tree, allowing for close contact and similar range use (Struhsaker, 2010). Foraging movements by an individual in the group affect others by limiting locations that are considered safe or desirable. Through combined individual decisions, group movement patterns are produced (Fig. 2).

Disease spreads through the system through proximity of susceptible host to infectious individuals. Within a specific social group the speed of the infection will spread based on the dynamics of the social group, whereas inter group transmission is driven through shared use of the forest landscape. Within the simulation model the driver behind both these transmission routes is the characteristics of the landscape and how they affect red colobus social groups (i.e., group spread, shared resource sites, daily movement patterns). Through movement and foraging choices of these social groups transmission between and within groups of the microparasite agent leads to the emergence of host-parasite dynamics.

\subsubsection{Sensing}

The red colobus agent is assumed to know the values of the resources and distances to all resource sites within their search radius. They are also able to remember the location and quantity of past resource sites that contained a significantly higher amount of resources (i.e., spatial memory); it is assumed that the amount remembered at these resource sites will increases by the same regrow factor as the resource agent, allowing red colobus agents to estimate resource levels at these sites while not within their search radius. The red colobus agent is also assumed to know the location of other primates within its search radius. The microparasite and resource agents do not have any sensory capabilities.

\subsubsection{Interaction}

The interaction between the host red colobus agent and a microparasite agent is defined by the microparasite. The microparasite will change the status of the red colobus agent based on its stage of development. It will also, at the end of its life cycle either remove the host from the simulation (death) or give it a certain amount of immunity (modeled as a resistance to subsequent infections). Red colobus agents will also remove resources from resource agents (polygons) lowering total resources available in that resource agent for other red colobus agents.

\subsubsection{Stochasticity}

The placement of a red colobus agent within a resource polygon, once selected by the agent as a desired polygon to move towards, is randomly chosen, representing the limited information concerning fine scale within-group movements. The transmission of the microparasite, from one agent to another, is then modeled as a stochastic process in which proximity is a factor. This represents our uncertainty in the events leading to a successful transmission from an infected host to that of a susceptible host. Stochasticity is also included in determining the outcome of the infection, resulting in the death of the host or the host acquiring a certain amount of immunity. Again this represents incomplete knowledge with respect to factors leading to the death of a host.

\subsection{Initialization}

The primary input into the model is the distribution of red colobus resources, in which we aim to reproduce distribution patterns observed at our study site. To accomplish this we use forest structural data. We fit a pareto distribution, a statistical distribution used often to fit data showing a inverse J-shape, to the age class distribution of trees within our study site (Pareto shape 1.5185, location 10; Kolmogorov-Smirnov test; $p<0.05$ ). A forest age class distribution is essentially a histogram classing individual trees by their sizes, measured here by their diameter at breast height (DBH). From these distributions we can estimate the distribution of resources available to red colobus, assuming a direct 
relationship between DBH of trees and food availability. The relationship between DBH and the availability of red colobus resources is one that has been found at multiple sites (Chapman et al., 1992; Rovero and Struhsaker, 2007; Snaith and Chapman, 2008). Our forest plot data showed a linear relationship between average DBH of a plot and the amount of red colobus food found within that plot (Adjusted $R$ square $=0.627, p<0.01$ ), collected from the 26 forest plots. We were able to then populate our model environment, a 225 ha grid with $30 \mathrm{~m} \times 30 \mathrm{~m}$ grid squares, with DBH values selected from this fitted distribution. Each grid cell, now containing DBH values, is then used as an estimate for the amount of resources available to the red colobus. By including a variable "DBHtoFood" to multiply the value of DBH within all sites, we are able to reproduce the linear relationship between red colobus food and DBH. By using a fitted distribution to simulate forest stand structure (age class distribution of forest trees) we are able to simply change the shape of the distribution to redistribute resources in our simulated environment, creating heterogeneous or homogeneous resource landscapes, mimicking patterns seen at our study site. A final step is added where a common conversion factor is multiplied to each resource cell to maintain equal amounts of resources between simulation runs.

This resource landscape is then populated with five distinct social groups, of different sizes $(70,25,84,45,40)$, as measured by Snaith and Chapman (2008), representing average density of red colobus in our study area. The starting locations of these groups are randomly chosen, but fixed between runs. Each group is assigned with an initial memory of significant resource sites within an expected home range, based on data on group and home range size (Snaith and Chapman, 2008). One individual from the same group is randomly chosen on the first step and becomes exposed at $t=1$, initiating the disease transmission process (see Table 1).

\subsection{Submodels}

\subsubsection{Primate agent energy balance}

A simple energy balance was created based on observations of the time spent feeding by red colobus monkeys in the field. Within our study area, red colobus spend on average $43 \%$ of their time feeding (Snaith and Chapman, 2008). Thus, the assumption was made that this represents their required food effort per day. Therefore, out of 26 steps, which represents one day in the simulation, approximately 11 of these steps should be feeding events. By arbitrarily choosing 100 as a target energy level, the energy gain per feeding must be $100 / 11$. The red colobus agent will also lose $100 / 26$ units of energy each time step, mimicking metabolic requirements and will result in a total loss of 100 units of energy each day, and are considered to be "hungry" when below the target energy level.

\subsubsection{Primate agent safety rules}

The balance between safety and feeding competition, for the red colobus agent, is accomplished by allowing the agent to modify its parameter "safe neighbour size." The number of neighbours that the red colobus agent needs to be considered safe will increase when feeding is successful and decrease when feeding targets are not being met. A primate agent considers itself safe when a sufficient number of its group members are nearby; where "nearby" is defined by a circle of radius $X$ around the agent in question. The value of $X$ is determined by a function of the red colobus' social group size (safe radius $=(1 \mathrm{~m} /$ individual $) \times$ group size $)$, allowing individuals within larger groups to be aware of more group mates.

Each primate will measure its success in feeding by counting the number of feeding events per day. If the primate is feeding on average 11 steps per day, i.e., $43 \%$ of the day as observed in our study area, then the number of neighbours to be considered safe is increased. If it is averaging less than 10 feeding steps per day the number of neighbours is lowered. The primate will also decrease safe neighbour size when energy levels are lower than half the target energy level, indicating a stress period, and increase safe neighbour size when energy targets are exceeded indicating very favourable conditions.

If the primate agent does not consider itself in a safe position, i.e., not enough neighbours nearby, it will move towards its social group. It does this by locating its closest group members, considering only the number of neighbours it needs to be considered safe, and moves to the center of that group. If the center of these nearby members is farther than $50 \mathrm{~m}$ it the agent will move $50 \mathrm{~m}$ towards that center. This value of $50 \mathrm{~m}$ is based on observations that one rarely sees animals further than this from other group members and this value is thought to be approximately the limit with which an individual could visually see another group member through the canopy (Chapman, unpublished data).

\subsubsection{Primate agent foraging rules}

Primates forage by choosing the best food site based on a simple rule comparing the distance to the food site and the amount of

Table 1

Model input parameters, both those calibrated and non-calibrated, included within the simulations.

\begin{tabular}{|c|c|c|c|c|}
\hline Agent & Parameter & Value & Units & References \\
\hline \multicolumn{5}{|c|}{ Calibrated parameters (POM approach) } \\
\hline \multirow[t]{8}{*}{ Red colobus } & Energy gain per feeding & $100 / 11$ & Energy & Snaith and Chapman (2008) \\
\hline & Energy loss per step & $100 / 26$ & Energy & Snaith and Chapman (2008) \\
\hline & Target energy level & 100 & Energy & Snaith and Chapman (2008) \\
\hline & Search radius & 100 & Meters & - \\
\hline & Safe radius & Group size & Meters & - \\
\hline & Safe neighbour size \pm & 5 & Agents & - \\
\hline & Significant DBH size & 50 & $\mathrm{~cm}$ & - \\
\hline & Weight of known sites & 2 & - & - \\
\hline \multirow[t]{3}{*}{ Environment } & DBH to food & 6 & Energy/DBH & - \\
\hline & Grow back rate & 5 & Energy/step & - \\
\hline & Pareto location parameter & 10 & - & Chapman (unpublished data) \\
\hline \multirow[t]{5}{*}{ Microparasite } & Transmission: contact & 2.5 & $\%$ & - \\
\hline & Transmission: droplet & 1.25 & $\%$ & - \\
\hline & Transmission: airborne & 0.625 & $\%$ & - \\
\hline & Incubation period & 19 & Days & Hutin et al. (2001) \\
\hline & Infectious period & 6 & Days & Hutin et al. (2001) \\
\hline \multicolumn{5}{|c|}{ Non-calibrated parameters } \\
\hline Environment & Pareto shape parameter & $0.5-4.0$ & - & Chapman (unpublished data) \\
\hline \multirow[t]{2}{*}{ Microparasite } & Virulence & $0-100$ & $\%$ & - \\
\hline & Immunity developed & 0,100 & $\%$ & - \\
\hline
\end{tabular}


resource at the site. A food site index is created, using this rule, to allow a red colobus agent to choose the best site from sites considered to be safe (Boyer et al., 2006; Ramos-Fernandez et al., 2006). Food sites are considered safe if, once moved, the agent would have enough neighbours nearby.

Food site index $=\frac{\text { distance }(\mathrm{m})}{\text { food (energy) }}$

Best food site $=\min ($ food site index $)$

Once a food site is chosen, the red colobus agent will then move towards it. If the food site is contained within the agent's search radius, the agent is assumed to move directly to the site. If the desired food source is beyond this threshold (i.e., from a remembered site), then the agent will move towards it, choosing a safe site by again comparing food sites with the food site index, using the distance to the remembered site as a factor.

We also included a variable, "weight of known sites", to allow remembered sites to potentially have more draw when choosing possible food sites. This represents our assumptions that red colobus use spatial memory in making foraging decisions and will favour past sites in which they have had successful feeding. The value of "weight of known sites" is divided from the food site index of a remembered site, thereby increasing its attraction to a red colobus agent (i.e., if "weight of known sites" is set to 2 a remembered site will be 2 times more attractive than a non-remembered site of equal resources and distance).

The amount of spatial memory used by a red colobus agent was controlled with the variable "significant DBH". If any resources site was above this value the red colobus considered it to be a significant site and would add it to its list of remembered sites. By increasing and decreasing the significant DBH value we could correspondingly increase or decrease the amount of memory used by the red colobus agent in making foraging decisions.

\subsubsection{Microparasite transmission}

The microparasite agent within our model is able to replicate itself in nearby hosts, where the success of transmission is a function of the distance to other hosts. This function is represented here as a discrete function representing probability of transmission based on stages in hosts proximity, modeling transmission routes of contact, droplet range (from coughing/sneezing), and finally airborne exposure. Parameters values for transmission probabilities were estimated by, starting from low values (close to zero), increasing the probability of transmission until population wide exposures were possible within our simulation, modeling a highly contagious pathogen.

$$
\begin{aligned}
& \text { Probability of transmission } \\
& \quad= \begin{cases}\text { If } x \leq 2.5 \mathrm{~m} & p_{\text {contac }}=0.025 \% \\
\text { If } 2.5 \mathrm{~m}<x<5 \mathrm{~m} & p_{\text {droplet }}=0.0125 \% \\
\text { If } 5 \mathrm{~m}<x<10 \mathrm{~m} & p_{\text {airborne }}=0.00625 \%\end{cases}
\end{aligned}
$$

Once transmission occurs, the new microparasite agent will age during its incubation period only becoming infectious after the incubation period has elapsed. At the end of the infectious period the microparasite's virulence parameter will determine the probability that the microparasite will kill the host, in which case both the host and microparasite are removed from the simulation. This represents the only source of mortality in the model. We assume here that virulence is independent of the mode of transmission and that the infection and incubation times are relatively static (see Kramer-Schadt et al., 2009 for discussion).

\subsubsection{Resource agent re-grow rate}

The resource agent (grid square) holds a certain amount of resources, which the red colobus can "eat" and deplete (Snaith and Chapman, 2005). A resource agent, if reduced by foraging, is able to then re-grow at a constant rate ("grow back rate") every time step, until it reaches its set maximum resource level; which is its initial value at the start of the simulation.

\subsection{Model predictions and observations}

To parameterize and build the model we employed "model cycling" with a pattern orientated modeling (POM) approach (Grimm and Railsback, 2005; Kramer-Schadt et al., 2007). With this, we compared patterns of behaviour from our model to selected performance criteria that we have defined. These selected performance criteria were geared towards aspects of the system which we thought were essential in determining transmission rates, consisting of: monthly home range size of red colobus groups, average daily group movement, and their average spread.

Simulated groups of red colobus that followed simple rules balancing safety requirements against increased food competition, were able to reproduce expected trends observed in the field: larger groups foraged over larger home ranges, traveled longer distances per day, had a larger group spread and needed to spend more time moving per day than smaller groups (Snaith and Chapman, 2008; Chapman and Chapman, 2000). In lower quality habitats, groups increased their home ranges, travel distance per day, group spread, and time spent moving per day. These trends are consistent with empirical data on group movement patterns when habitat quality has been taken into account (Chapman et al., 2006; Snaith and Chapman, 2008). These patterns held for a wide variety of resource landscapes, as well as different parameterizations of our assumed decision rules. This suggests that our assumptions have captured important components of primate group movement and behaviour. To verify that our simulation could adequately reproduce movement behaviours, we attempted to parameterize the simulation to reproduce the performance criteria for a group of 70 individuals. Compared to our observed data (simulated value/observed value), we were able to test the fit of our models; $86 \%$ for average monthly home range, $75 \%$ for average day range, and $67 \%$ for average group spread. As a validation step, we varied group size without changing parameterization and compared the simulated results to our observed field data (Fig. 3). The model was able to reproduce trends in our observed data, suggesting that our model has captured many elements of group movement behaviour in red colobus groups.

If we examine our model, overall the values for our performance criteria were consistently underestimated. We attribute this to two potential factors. First, during our calibration and construction of the model, we focused on one group of 70 individuals, and did not take increased movement due to food competition from multiple group scenarios into account. We also attribute some of the underestimations to be due to our relatively simple rules governing social interactions between individuals of a group. The omission of ranking or demographics in our social groups somewhat complicates group movement behaviour within the model, as every primate agent has the same weight in group movement decisions, causing what seems to be, in some cases, indecision in group movement. With the inclusion of higher ranked individuals or group demographics, we might be able to better fit model predictions to observations in average daily movements and home range sizes.

We also found patterns that we did not expect in the simulated groups, but are seen in wild populations of red colobus. Observations in the field have been made of groups, mostly large groups, breaking into smaller subgroups temporarily to forage separately, and then re-group. This is termed fission-fusion of groups (Aureli et al., 2008). With our simple assumptions regarding the trade-off of 

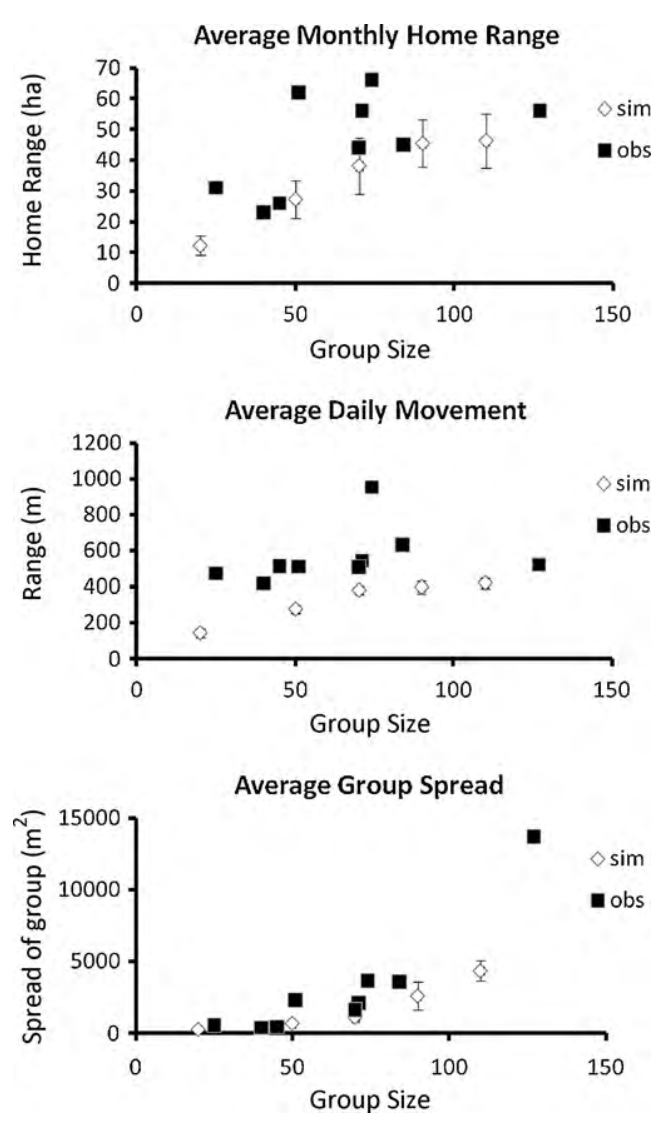

Fig. 3. Model predictions of performance criteria (average monthly home range, average spread of group and average daily movements) while holding environmental variables constant and only varying group size. Observed values are represented by squares, and diamonds represent simulated values. Simulations results follow trends in observed data.

safety and food competition within a group, we see fission-fusion dynamics in simulated groups undergoing food stress, in such cases as; large groups ( $\sim 100+$ individuals) or with groups in low resource landscapes.

\section{Results}

When the simulation was run the microparasites spread within social groups, showing a continuous cycling when immunity was not developed and only once when immunity was developed. We also observed the microparasite spread between social groups. By varying forest composition and hence the distribution of resources within the simulation, we were able to test how changes in resource distribution could affect transmission rates in red colobus populations.

Spatial memory, "SigDBH", was found to be an important factor, influencing the direction of the effects of the landscape. When the spatial memory of groups was not considered in the simulations, creating more homogeneous landscapes increased the ranging behaviour of primate groups, consistently increasing the probability that groups would contact each other. However, when spatial memory was considered in the model, transmission rates were overall consistently higher, and revealed contrary results. When spatial memory was considered in the simulations, highly homogeneous landscape had relatively lower contact rates; with the rate of contact between groups increasing with increasing resource heterogeneity. However at a point, in highly heterogeneous landscapes, the probability of contact between groups decreased. This shift from an increase to a decrease in the rate of contact can be seen
Effects of The Density of High Resource Sites

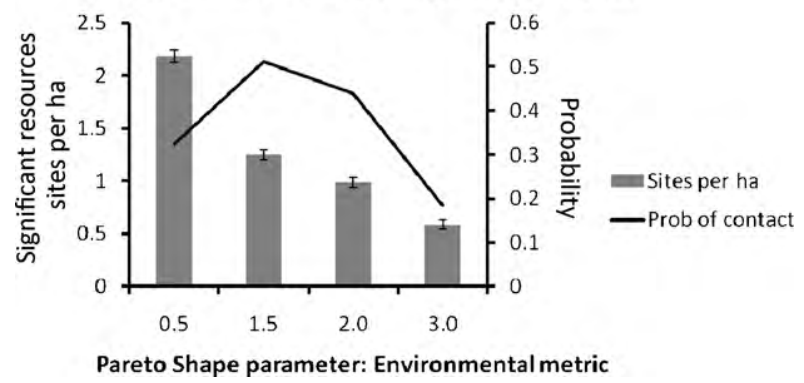

Fig. 4. Effects of density of high resource sites on the probability of contact between groups. The probability of contact is estimated from the percentage of simulations in which all groups became infected by the microparasite (simulation results from a total of 297 runs).

as a reflection of the number of remembered sites held in common between groups. In landscapes with higher number of significant sites, a large number of resources are shared by multiple groups, such that two or more groups will choose the same site at a given time only rarely. This probability of contact increases as the number of sites decreases, allowing for smaller shared memories of significant sites and an increased chance of two or more groups choosing to visit the same site at the same time. As shared memory decreases further, eventually approaching zero, the probability of contacting other groups begins to decrease; reaching levels of transmission similar to model runs without spatial memory. Our model therefore predicts that the density of high resource sites influences the probability of contacting other groups (Fig. 4).

The cost of the parasite to the host, modeled here as the probability that the parasite will kill the host after its infectious period, had an effect on overall transmission within the population of red colobus hosts. When immunity to the parasite was not acquired by the hosts, highly virulent microparasites increase overall population survival; with maximum population loss at an intermediate virulence value. At higher virulence, infectious hosts die before being able to infect other hosts, while also reducing the size of their groups and hence reducing their groups' movement. This is somewhat expected from epidemiological theory, regarding parasites that are reliant on their host movement for transmission success (Ewald, 1995). In regards to how the distribution of resources affects this trade-off we find that the virulence value in which the population is reduced the most shifts as the distribution of resources facilitates overall contact rates within the population, enabling more virulent strains to have a greater impact on the population as well as to spread over larger areas (Fig. 5).

\section{Discussion}

Insights from this model focusing on the effects of changing resource distributions lead us to predict that resource clumping within habitat patches is likely to be an important factor affecting transmission rates within populations of animals that use patchy environments. Many animal species, including red colobus, use spatially aggregated resources, suggesting that this may represent a general phenomenon. The model also highlights the fact that transmission rates would be spatially dependant, with certain parts of the landscape being hot spots of transmission, such as habitats with few high resource sites.

To generalize our results, we found that there were two forest characteristics that described the distribution of resources and created spatial "hot spots" of transmission: (1) overall variation in forest tree age classes and (2) the number of high resource sites. The former represented a level of heterogeneity in the forest, whereas the latter represented the effects of shared resource sites; both 

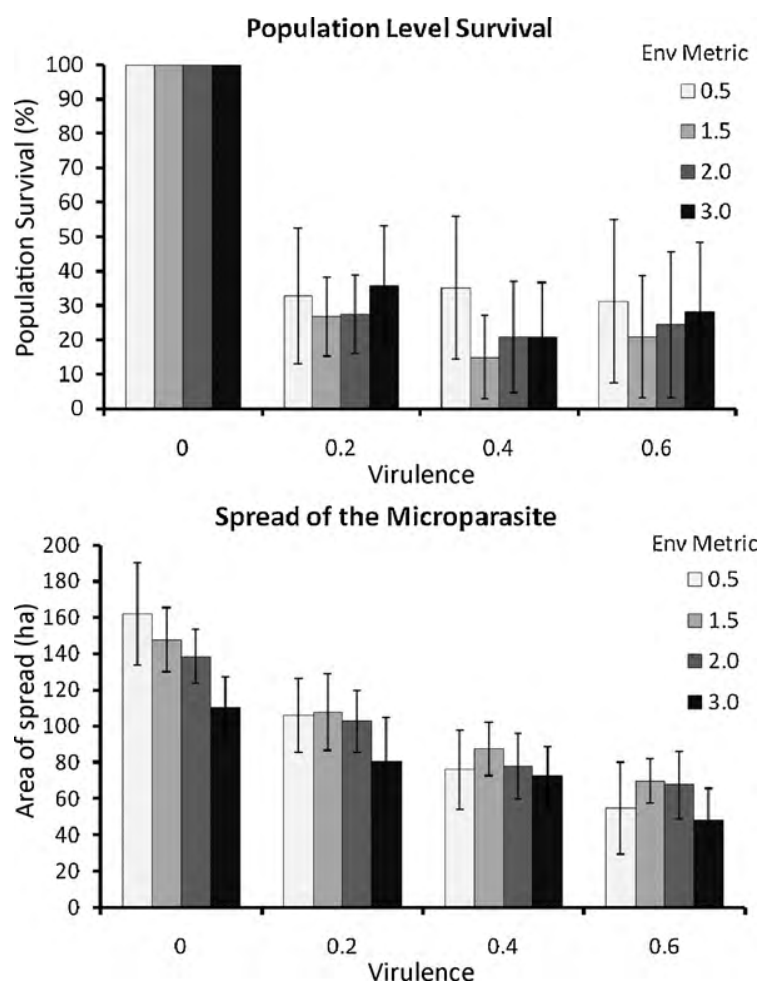

Fig. 5. Effects of varying resource distribution on (a) overall population survival rates, and (b) spread of the microparasite (ha). The environmental metric, pareto shape parameter, is used to modify the distribution of resources in the simulation. We see that population survival is lower and overall microparasite spread is higher at an optimal resource distribution (pareto shape parameter: 1.5). (Simulation was run a minimum of 300 times for each environmental metric: $0.5,1.5,2.0$, and 3.0).

are not entirely independent of each other. These two characteristics represented two different processes, and their different effects reflect the different spatial scales on which they operate. Changes to the level of heterogeneity of the landscape affects the foraging patterns of groups at the scale of neighbouring resources, influencing short range movement patterns and overall spread of the groups and effecting transmission dynamics within the group. On the other hand, the number of high resource sites affects foraging patterns at spatial scales closer to that of a group's home range, influencing long range movement patterns and affecting transmission between groups. The relative importance of these two characteristics in determining overall parasite transmission was determined in our simulation by the importance that spatial memory plays in determining red colobus movement patterns, suggesting that the density of high resource sites would be the most significant factor in determining the spread of the microparasite.

Species of non-human primates are thought to retain spatial memory with which they develop cognitive maps of their environments resources (Poucet, 1993; Di Fiore and Suarez, 2007; Janson and Byrne, 2007). Our model suggests that resources sites which are shared in memories of individuals in a group would be important for the transmission of disease. We therefore predict that a species may limit its contact with other groups by following different evolutionary strategies, such as developing territoriality or holding strong preference for familiar feeding sites. We might therefore expect that in heavily parasitized communities, factors that reduce the similarities of inter group cognitive maps might be selected.

If we apply the simulation results to our specific study site, to nearby areas that were selectively logged in the late 1960 s, we can compare forest structure characteristics of undisturbed and disturbed areas. We observe a general trend between the intensity of logging and a decrease in the proportion of large trees and an increase in the proportion of mid-sized trees. This suggests that logged areas, with little to no large trees, will produce a resource landscape with very few high values food sites, whereas unlogged areas consist of many high value resource sites. From our plot data (5 plots within logged area; 11 from the undisturbed area) we gain an estimate of significant resource sites (trees $>50 \mathrm{~cm} \mathrm{DBH}$ ) within each area: unlogged 39.5 significant sites/ha, logged 18 significant sites/ha. From the results of our model we would predict that, in the logged areas, the density of resources would act to increase transmission rates between groups leading to less variation in disease states among groups and possibly an increase in the intensity of parasitism. However, it must be noted that this prediction relies on the assumption that the estimated high value resource sites are randomly distributed and that host densities are similar in both areas, as well as that logging does not induce other stressors that could influence immunity (e.g., a decrease in available foods).

GIS capabilities were embedded and used within our agentbased model, following past approaches which have highlighted the benefits of ABM/GIS systems (Brown et al., 2005). The GIS capabilities allowed us to develop a complex landscape on which we could run our individual based SEIR model, similar to approaches taken by Linard et al. (2009), and to apply such a model in the context of an important wildlife host-parasite system. As long as the context considered is a general one (e.g., organisms using patchy resources), then the model will be broadly applicable to a number of wildlife-disease interactions.

The fact that red colobus group movements and foraging patterns are closely associated with environmental characteristics (Snaith and Chapman, 2008), creates an opportunity to simulate how changes to environmental characteristics can affect aspects of host parasite interactions within a population. A similar approach, using detailed environmental data along with behavioural data, should be applicable to other host-parasite systems as well. Examples of systems that would benefit from these approaches might be: (1) directly transmittable parasites reliant on a mobile host for transmission, where connectivity amongst the host population is determined from landscape properties (e.g., rabies), (2) parasites who have a life stage in the external environment and are relatively immobile, where overlap and range use of the definitive host would be an important (e.g., gastro-intestinal parasites), (3) parasites in which a specific host is responsible for spreading disease amongst separate reservoir populations (e.g., Lyme disease, poxviruses, ebola virus). The value of our study is therefore not only to predict how disease transmission in red colobus in Kibale might respond to changing forest structure, but also to provide ground work for predicting similar effects in other host species where environmental characteristics are important drivers affecting transmission of parasites. Predictions from such models should be useful in constructing informed management plans for endangered species that account for the transmission of infectious disease across real landscapes (depicted with remote sensing data), as well as for predicting the disease-related effects of a changing climate, habitat fragmentation, logging, or other similar anthropogenic changes to wildlife habitats.

\section{Acknowledgements}

Funding for the Ugandan research was provided by Canada Research Chairs Program, Wildlife Conservation Society, Natural Science and Engineering Research Council of Canada, National Geographic, and the National Science Foundation to CC, and by the Morris Animal Foundation through its support of the Kibale EcoHealth Project (award \#D07ZO-024) and the University of Wisconsin School of Medicine and Public Health from The Wisconsin Partnership Program to TG. Support for the modeling work was 
provided by Natural Science and Engineering Research Council of Canada (RS, CC). Permission to conduct the research in Uganda was given by the National Council for Science and Technology and the Uganda Wildlife Authority. We would like to extend a special thanks to Mel Lefebvre, Lauren Chapman, Julian Zhunping, and Andre Costopoulos for helpful comments on this manuscript, as well as to Margaret Kalácska for providing access to computer resources.

\section{References}

Aureli, F., Schffner, C.M., Boesch, C., Bearder, S.K., Call, J., Chapman, C.A., Connor, R., Di Fiore, A., Dunbar, R.I.M., Henzi, S.P., Holekamp, K., Korstjens, A.H., Layton, R., Lee, P., Lehmann, J., Manson, J.H., Ramos-Fernandez, G., Strier, K.B., Van Schaik, C.P., 2008. Fission-fusion dynamics: new research frameworks. Curr. Anthropol. 49, 627-654.

Bennett, D.A., Tang, W., 2006. Modelling adaptive, spatially aware, and mobile agents: Elk migration in yellowstone. Int. J. Geogr. Inf. Sci. 20, 10391066 .

Bian, L., 2004. A conceptual framework for an individual-based spatially explicit epidemiological model. Environ. Plann. B 31, 381-395.

Boyer, D., Ramos-Fernandez, G., Miramontes, O., Mateos, J.L., Cocho, G., Larralde, H., Ramos, H., Rojas, F., 2006. Scale-free foraging by primates emerges from their interaction with a complex environment. Proc. R. Soc. B 273, 1743-1750.

Brown, D., Riolo, R., Robinson, D.T., North, M., Rand, W., 2005. Process and data models: toward integration of agent-based models and GIS. J. Geogr. Syst. 7, 25-47.

Bryson, J.J., Ando, Y., Lehmann, H., 2007. Agent-based modelling as scientific method: a case study analysing primate social behaviour. Philos. Trans. R. Soc. B 362, 1685-1698.

Chapman, C.A., Chapman, L.J., 2000. On the move: how and why animals travel in groups. In: Boinski, S., Garber, P.A. (Eds.), Determinants of group size in social primates: The importance of travel costs. University of Chicago Press, Chicago, pp. $24-42$.

Chapman, C.A., Chapman, L.J., 2002. Foraging challenges of red colobus monkeys: influence of nutrients and secondary compounds. Comp. Biochem. Physiol. A $133,861-875$.

Chapman, C.A., Chapman, L.J., Bjorndal, K.A., Onderdonk, D.A., 2001. Application of protein-to-fiber ratios to predict colobine abundance on different spatial scales. Int. J. Primatol. 23, 283-310.

Chapman, C.A., Chapman, L.J., Jacob, A.L., Rothman, J.M., Omeja, P., Reyna-Hurtado, R., Hartter, J., Lawes, M.J., 2010. Tropical tree community shifts: implications for wildlife conservation. Biol. Conserv. 143, 366-374.

Chapman, C.A., Chapman, L.J., Wrangham, R., Hunt, K., Gebo, D., Gardner, L., 1992. Estimators of fruit abundance of tropical trees. Biotropica 24, 527-531.

Chapman, C.A., Gillespie, T.R., Goldberg, T.L., 2005a. Primates and the ecology of their infectious diseases: how will anthropogenic change affect host-parasite interactions? Evol. Anthropol. 14, 134-144.

Chapman, C.A., Struhsaker, T.T., Lambert, J.E., 2005b. Thirty years of research in Kibale National Park, Uganda, reveals a complex picture for conservation. Int. J. Primatol. 26, 539-555.

Chapman, C.A., Peres, C.A., 2001. Primate conservation in the new millennium: the role of scientists. Evol. Anthropol. 10, 16-33.

Chapman, C.A., Saj, T.L., Snaith, T.V., 2007. Temporal dynamics of nutrition, parasitism, and stress in colobus monkeys: implications for population regulation and conservation. Am. J. Phys. Anthropol. 134, 240-250.

Chapman, C.A., Wasserman, M.D., Gillespie, T.R., 2006. Behavioural patterns of colobus in logged and unlogged forests: the conservation value of harvested forests. In: Newton-Fisher, E., Notman, H., Reynolds, V., Patterson, J.D. (Eds.), Primates of Western Uganda. Springer, New York, pp. 373-390.

Daszak, P., Cunningham, A., Hyatt, A., 2001. Anthropogenic environmental change and the emergence of infectious diseases in wildlife. Acta Trop. 7, 103-116.

Daszak, P., Cunningham, A.A., 2003. Anthropogenic change, biodiversity loss, and a new agenda for emerging diseases. J. Parasitol. 89, S37-S41.

Davies, T.J., Pedersen, A.B., 2008. Phylogeny and geography predict pathogen community similarity in wild primates and humans. Proc. R. Soc. Biol. Sci. Ser. B 275, 1695-1701.

Di Fiore, A., Suarez, S.A., 2007. Route-based travel and shared routes in sympatric spider and woolly monkeys: cognitive and evolutionary implications. Anim. Cogn. 10, 317-329

Ewald, P.W., 1995. The evolution of virulence: a unifying link between parasitology and ecology. J. Parasitol. 81, 659-669.

Formenty, P., Hatz, C., Le Guenno, B., Stoll, A., Rogenmoser, P., Widmer, A., 1999. Human infection due to Ebola virus, subtype Cote d'Ivoire: clinical and biologic presentation. J. Infect. Dis. 179 (Suppl. 1), S48-S53.

Gillespie, T.R., Chapman, C.A., 2006. Prediction of parasite infection dynamics in primate metapopulations based on attributes of forest fragmentation. Conserv. Biol. 20, 441-448.

Goldberg, T.L., Chapman, C.A., Cameron, K., Saj, T., Karesh, W.B., Wolfe, N.D., Wong, S.W., Dubois, M.E., Slifka, M.K., 2008a. Serologic evidence for novel poxvirus in endangered red colobus monkeys, western Uganda. Emerg. Infect. Dis. 14, 801-803.
Goldberg, T.L., Gillespie, T.R., Rwego, I.B., Estoff, E.L., Chapman, C.A., 2008b. Forest fragmentation as cause of bacterial transmission among nonhuman primates, humans, and livestock, Uganda. Emerg. Infect. Dis. 14, 1375-1382.

Goldberg, T.L., Sintasath, D.M., Chapman, C.A., Cameron, K.M., Karesh, W.B., Tang S., Wolfe, N.D., Rwego, I.B., Ting, N., Switzer, W.M., 2009. Co-infection of Ugandan red colobus (Procolobus [Piliocolobus] rufomitratus tephrosceles) with novel, divergent delta-, lenti- and spuma- retroviruses. J. Virol. 83, 11318-11329.

Graczyk, T., Bosco-Nizeyi, J., Ssebide, B., Thompson, R., Read, C., Cranfield, M., 2002 Anthropozoonotic Giardia duodenalis genotype (assemblage) an infections in habitats of free-ranging human-habituated gorillas, Uganda. J. Parasitol. 88, 905-909.

Grimm, V., Berger, U., Bastiansen, F., Eliassen, S., Ginot, V., Giske, J., Goss-Custard, J., Grand, T., Heinz, S.K., Huse, G., Huth, A., Jepsen, J.U., Jørgensen, C., Mooij, W.M., Müller, B., Pe'er, G., Piou, C., Railsback, S.F., Robbins, A.M., Robbins, M.M., Rossmanith, E., Rüger, N., Strand, E., Souissi, S., Stillman, R.A., Vabø, R., Visser, U., DeAngelis, D.L., 2006. A standard protocol for describing individual-based and agent-based models. Ecol. Model. 198, 115-126.

Grimm, V., Railsback, S. (Eds.), 2005. Individual-Based Modeling and Ecology. Princeton University Press.

Hahn, B., Shaw, G., De Cock, K., Sharp, P., 2000. AIDS as a zoonosis: scientific and public health implications. Science 287, 607-614.

Hemelrijk, C., 2002. Despotic societies, sexual attraction and the emergence of male 'tolerance': an agent-based model. Behaviour 139, 729-747.

Hethcote, H.W., 2000. The mathematics of infectious diseases. Soc. Ind. Appl. Math. 42, 599-653.

Houghton, R.A., 1994. The worldwide extent of land-use change. Bioscience 44, 305-313.

Hutin, Y.J.F., Williams, R.J., Malfait, P., Pebody, R., Loparev, V.N., Ropp, S.L., Rodriguez, M., Knight, J.C., Tshioko, F.K., Khan, A.S., Szczeniowski, M.V., Esposito, J.J., 2001 Outbreak of human monkeypox, Democratic Republic of Congo, 1996-1997. Emerg. Infect. Dis. 7, 434-438.

Janson, C.H., Byrne, R., 2007. What wild primates know about resources: opening up the black box. Anim. Cogn. 10, 357-367.

Jones, K.E., Patel, N.G., Levy, M.A., Storeygard, A., Balk, D., Gittleman, J.L., Daszak, P., 2008. Global trends in emerging infectious diseases. Nature 451, 990-994.

Kaur, T., Singh, J., Tong, S., Humphrey, C., Clevenger, D., Tan, W., Szekely, B., Wang Y., Li, Y., Muse, E.A., Kiyono, M., Hanamura, S., Inoue, E., Nakamura, M., Huffman, M.A., Jiang, B., Nishida, T., 2008. Descriptive epidemiology of fatal respiratory outbreaks and detection of a human-related metapneumovirus in wild chimpanzees (Pan troglodytes) at Mahale Mountains National Park, Western Tanzania. Am. J. Primatol. 70, 755-765.

Kondgen, S., Kuhl, H., N'Goran, P.K., Walsh, P.D., Schenk, S., Ernst, N., Biek, R., Formenty, P., Matz-Rensing, K., Schweiger, B., Junglen, S., Ellerbrok, H., Nitsche A., Briese, T., Lipkin, W.I., Pauli, G., Boesch, C., Leendertz, F.H., 2008. Pandemic human viruses cause decline of endangered great apes. Curr. Biol. 18, 260-264.

Kramer-Schadt, S., Fernandez, N., Eisinger, D., Grimm, V., Thulke, H.-H., 2009. Individual variations in infectiousness explain long-term disease persistence in wildlife populations. Oikos 118, 199-208.

Kramer-Schadt, S., Revilla, E., Wiegand, T., Grimm, V., 2007. Patterns for parameters in simulation models. Ecol. Model. 204, 553-556.

Linard, C., Poncon, N., Fontenille, D., Lambin, E.F., 2009. A multi-agent simulation to assess the risk of malaria re-emergence in southern France. Ecol. Model. 220 160-174.

Mittermeier, R.A., Ratsimbazafy, J., Rylands, A.B., Williamson, L., Oates, J.F., Mbora, D. Ganzhorn, J.U., Rodríguez-Luna, E., Palacios, E., Heymann, E.W., Kierulff, M.C.M., Yongcheng, L., Supriatna, J., Roos, C., Walker, S., Aguiar, J.M., 2007. Primates in peril: the world's 25 most endangered primates, 2006-2008. Primate Conserv. $22,1-40$.

Nunn, C.L., 2009. Using agent-based models to investigate primate disease ecology. In: Huffman, M.A., Chapman, C.A. (Eds.), Primate Parasite Ecology. Cambridge University Press, New York.

Nunn, C.L., Thrall, P.H., Stewart, K., Harcourt, A.H., 2008. Emerging infectious diseases and animal social systems. Evol. Ecol. 22, 519-543.

Ostfeld, S.R., Glass, E.G., Keesing, F., 2005. Spatial epidemiology: an emerging (or re-emerging) discipline. Trends Ecol. Evol. 20, 328-336.

Patz, J.A., Daszak, P., Tabor, G.M., Aguirre, A.A., Pearl, M., Epstein, J., Wolfe, N.D., Kilpatrick, A.M., Foufopoulos, J., Molyneux, D., Bradley, D.J., Working Group on Land Use Change and Disease Emergence, 2004. Unhealthy landscapes: policy recommendations on land use change and infectious disease emergence. Environ. Health Perspect. 112, 1092-1098.

Perez, L., Dragicevic, S., 2009. An agent-based approach for modeling dynamics of contagious disease spread. Int. J. Health Geogr. 8, 50.

Plowright, R.K., Sokolow, S.H., Gorman, M.E., Daszak, P., Foley, J.E., 2008. Causal inference in disease ecology: investigating ecological drivers of disease emergence. Front. Ecol. Environ. 6, 420-429.

Potts, M., 2007. Population and environment in the twenty-first century. Popul. Environ. 28, 204-211.

Poucet, B., 1993. Spatial cognitive maps in animals: new hypotheses on their structure and neural mechanisms. Psychol. Rev. 100, 163-182.

Ramos-Fernandez, G., Boyer, D., Gomez, V.P., 2006. A complex social structure with fission-fusion properties can emerge from a simple foraging model. Behav. Ecol. Sociobiol. 60, 536-549.

Rich, S.M., Leendertz, F.H., Xu, G., LeBreton, M., Djoko, C.F., Aminake, M.N., Takang, E.E., Diffo, J.L., Pike, B.L., Rosenthal, B.M., Formenty, P., Boesch, C., Ayala, F.J., Wolfe, N.D., 2009. The origin of malignant malaria. Proc. Natl. Acad. Sci. U.S.A. 106, 14902-14907. 
Roche, B., Guégan, J.-F., Bousquet, F., 2008. Multi-agent systems in epidemiology: a first step for computational biology in the study of vector-borne disease transmission. BMC Bioinformatics 9 (art. no. 435).

Rovero, F., Struhsaker, T.T., 2007. Vegetative predictors of primate abundance: utility and limitations of a fine-scale analysis. Am. J. Primatol. 69, 1242-1256.

Sellers, W.I., Hill, R.A., Logan, B.S., 2007. An agent-based model of group decision making in baboons. Philos. Trans. R. Soc. B 362, 1699-1710.

Sengupta, R., Sieber, R., 2007. Geospatial agents, agents everywere. Trans. GIS 11, 483-506.

Snaith, T.V., Chapman, C.A., 2005. Towards an ecological solution to the folivore paradox: patch depletion as an indicator of within-group scramble competition in red colobus monkeys (Piliocolobus tephrosceles). Behav. Ecol. Sociobiol. 59, 185-190.

Snaith, T.V., Chapman, C.A., 2008. Red colobus monkeys display alternative behavioral responses to the costs of scramble competition. Behav. Ecol. 19, 12891296.
Struhsaker, T.T., 1975. The Red Colobus Monkey. Chicago University Press, Chicago. Struhsaker, T.T., 1997. Ecology of an African Rain Forest: Logging in Kibale and the Conflict between Conservation and Exploitation. University Press of Florida Gainesville, Florida.

Struhsaker, T.T., 2005. Conservation of red colobus and their habitats. Am. J. Primatol. $26,525-538$.

Struhsaker, T.T., 2010. The Red Colobus Monkeys: Variation in Demography, Behavior, and Ecology of Endangered Species. Oxford University Press, Oxford.

Te Boekhorst, I.J.A., Hogeweg, P., 1994. Self-structuring in artificial "chimps" offers new hypotheses for male grouping in chimpanzees. Behaviour 130 $229-252$.

United Nations, 2009. World Population Prospects: The 2008 Revision, Highlights. Department of Economic and Social Affairs, Population Division, Working Paper No. ESA/P/WP.210.

Wolfe, N.D., Dunavan, C.P., Diamond, J., 2007. Origins of major human infectious diseases. Nature 447, 279-283. 